\title{
LA EUTANASIA Y EL TRASPLANTE DE ÓRGANOS. DE FRENTE A LA MUERTE: LAS PREGUNTAS NO RESUELTAS*
}

\author{
Paolo BECCHI**
}

\section{Resumen:}

En las siguientes páginas el autor intenta un acercamiento a la cuestión de la muerte desde una perspectiva ética y jurídica. La idea fundamental que guía este trabajo es que la ética y el derecho modernos que se han ocupado de los dos temas bioéticos cruciales relativos al fin de la vida (la eutanasia y el trasplante de órganos) hace que surjan dos problemas de fondo que comúnmente se consideran resueltos y que, de acuerdo con el autor, no lo están. El primero es que algunos estudiosos sostienen la licitud de la eutanasia activa y consideran del todo obvio que sea el médico quien la lleve a cabo. Sin embargo, existen buenas razones para considerar que es precisamente el médico quien debería abstenerse de practicarla. El segundo es que hay otros que sostienen la licitud de los trasplantes post mortem y consideran también obvio que el sujeto del cual se toman los órganos sea ya un cadáver. En cambio existen buenas razones para considerar que actualmente cuando toman dichos órganos aún no están muertos. El autor sostiene que si así fuera, el tema de los trasplantes presentaría un insospechado punto de contacto con el de la eutanasia. El desarrollo del trabajo, en primer lugar se detiene en el problema de la eutanasia, posteriormente en el del trasplante de órganos donde se busca finalmente evidenciar el punto de contacto entre las dos problemáticas.

* Traducción de Edith Cuautle Rodríguez, realizada con el patrocinio de la Universidad de Lucerna, Suiza. El artículo que se publicará en Problema, es el primer capítulo del libro de Becchi, Paolo, La morte nell'età dellá tecnica. Lineamenti di tanatologia etica e giuridica.

** Profesor e investigador de la Universidad de Lucerna, Suiza y de la Universidad de Génova, Italia. 


\title{
PAOLO BECCHI
}

Palabras clave:

Eutanasia, trasplante de órganos, bioética, muerte.

\begin{abstract}
:
In this paper the author tries to approach the subject of death from a law and ethics perspective. The idea is that modern works in law and ethics that have studied two of the main topics of bio-ethics (euthanasia and organ transplants) still leave unresolved two main problems. The first problem is with the idea many authors have of defending the possibility of active euthanasia and consider it an obvious matter that doctors have to practice this type of euthanasia. But we have good reasons to consider that doctors are the ones that have to abstain from this practice. The second issue is with the defense of the possibility of post mortem transplants and how this practice is also considered obvious due to the fact that the person from whom these organs are withdrawn is dead. Here we also have good reasons according to the author for considering that the person from whom these organs are withdrawn is not dead. The author finally tries to establish a link between these two unresolved problems.
\end{abstract}

Keywords:

Euthanasia, Organ Transplant, Bioethics, Death. 
SumARIO: I. Premisa. II. El dilema de la eutanasia voluntaria. III. Lineamientos de una ética cadavérica. IV. Un corazón que late.

\section{PREMISA}

El modo en que han sido tratados los dos temas bioéticos cruciales referentes al fin de la vida (la eutanasia y el trasplante de órganos) hace que surjan dos problemas de fondo que comúnmente se consideran resueltos y que, de hecho, no lo están. El primero es que algunos sostienen la licitud de la eutanasia activa y consideran del todo obvio que sea el médico quien la lleve a cabo. Sin embargo, existen buenas razones para considerar que es precisamente el médico quien debería abstenerse de practicarla. El segundo es que hay otros que sostienen la licitud de los trasplantes post mortem y consideran también obvio que el sujeto del cual se toman los órganos sea ya un cadáver. En cambio existen buenas razones para considerar que actualmente cuando toman dichos órganos aún no están muertos. Si así fuera, el tema de los trasplantes presentaría un insospechado punto de contacto con el de la eutanasia.

En primer lugar nos detendremos en el problema de la eutanasia, después en el del trasplante de órganos en el que buscaremos, finalmente, evidenciar el punto de contacto entre las dos problemáticas.

\section{El DILEMA DE LA EUTANASIA VOLUNTARIA}

Enfrentaremos aquí el problema de la eutanasia limitándonos a considerar aquella forma particular que se presenta como intervención directa y activa mediante la cual se pone término a la vida, en ocasiones por piedad, de una persona afectada por un mal incurable y que ella misma solicita. ${ }^{1}$ Es el caso, en cierta forma, paradigmático de la eutanasia, en el

1 Para profundizar véase Becchi, P., Questioni vitali. Eutanasia e clonazione nell'attuale dibattito bioetico, Nápoles, Loffredo, 2001, pp. 15-77. 
que el enfermo que consciente del proceso irreversible de su enfermedad pide, plenamente lúcido, morir.

Lo primero que debemos cuestionarnos cuando un enfermo terminal pide morir es por qué lo pide: ¿qué empuja a un hombre a preferir la muerte respecto de una condición que, aunque sea comprometida, es aún una condición de vida?, ¿qué empuja a un hombre a preferir la nada antes que el tener algo de existencia?

Sin duda, es el hecho que tal condición cambia para él cada día, cada hora que pasa es insostenible. No siempre se trata solamente del dolor físico, sino del sufrimiento existencial que surge del sentirse como un peso para los demás, tal vez abandonado por sus familiares en el momento de extrema necesidad. La decisión de concluir rápidamente con la vida puede nacer de la terrible soledad en la que cae el enfermo a causa de su mal: la soledad en que se encuentra al estar muriendo y al abandonar ya toda esperanza, él no puede más que solicitar la anticipación de la muerte, que es de cualquier modo una amenaza inevitable. Considerada bajo esta tesitura la eutanasia nace por una falta de solidaridad producto de una sociedad intoxicada de hedonismo que esconde a los enfermos crónicos y a su sufrimiento detrás del telón de la vida social.

No pretendemos restar importancia a esta tesitura, que llamaremos "eutanasia de abandono",2 pero creo que sería desviar y reducir la cuestión interna de la eutanasia. Debemos admitir que también el enfermo no abandonado por sus familiares y tratado con toda la asistencia que necesita decida lúcidamente poner fin al prolongamiento de una vida que cada día que pasa pierde sentido. ¿Podemos negarle el derecho de morir en paz?

Una clara o neta respuesta afirmativa a esta pregunta puede, tal vez, solamente tener una base de concepción éti-

2 Utilizo aquí una locución que se introdujo en Italia no tanto en relación específica al tema de la eutanasia, en cuanto al problema del estado de abandono en el cual con frecuencia dejan a los ancianos crónicos no autosuficientes. Pero la expresión me parece que se adapta bien a nuestro discurso ( $c f r$. varios autores, Eutanasia da abbandono, Turín, Rosenberg \& Sellier, 1998). 
ca de inspiración religiosa y específicamente cristiana. Si la vida humana es un don de Dios, es sacra e inviolable, y esto significa que ni siquiera el hombre que sufre sin esperanza tiene el derecho de disponer de su vida. No hay argumentación más fuerte que ésta que considera ilícita la aplicación de la eutanasia. A decir verdad, si se permanece al interior de la perspectiva cristiana esta conclusión no admite recurso. Las reflexiones recientes de Hans Küng, ${ }^{3}$ aunque también se podrían citar otros ejemplos, parecerían en realidad demostrar lo contrario. Sin embargo, nos gustaría aventurarnos en estos senderos teológicos.

Cualquiera que sea el argumento teológico en contra de la disponibilidad de la vida resulta actualmente demasiado débil. La ética no se confunde con la fe, aquélla tiene necesidad de un fundamento racional, en última instancia siguiendo a Jonas también metafísico; ${ }^{4}$ sin embargo, si aspira a hablar indistintamente, universalmente a todos los hombres, no puede que callar sobre la trascendencia. La trascendencia no se dice, solamente se da. Por esto la ética no puede constituir — como quería Levinas 5 - el modelo de la revelación: la "visión de Dios" no es un acto moral, sino un acto de fe. Y la vida del hombre sólo a él le pertenece. Esto es tanto "para la muerte" como "para la vida": depende de él la decisión de mantenerse al borde del abismo, pero en todo momento es libre de arrojarse dentro. Y esto es porque no solamente él tiene un derecho a la vida, el derecho a no sufrir lesiones, sino que también a un derecho sobre su propia vida.

3 Küng, H., "Della dignità del morire”, en Küng, H. y Jens, W., Della dignità del morire. Una difesa della libera scelta, Milán, Rizzoli, 1996, pp. 13-104.

4 La aproximación jonasiana se encuentra en la parte monográfica de la quinceavo fascículo de Ragion Pratica, 2000, pp. 13-176.

5 Sobre este aspecto central de la reflexión de Levinas, cfr. Moscato, A., L'etica como linguaggio della trascendenza nell'opera di Emmanuel Levinas (1995), ahora en Moscato, A., Metafísica e intelligibilità. Studi di filosofia teoretica, Génova, Brigati, 2000, pp. 141-164. Cfr. también Camera, F., Spazio della trascendenza e significato dell'etica (1992) ahora en Camera, F., L'ermeutica tra Heidegger e Levinas, Brescia, Morcelliana, 2001, pp. 147-170. 
Cierto, se podría replicar observando que la indisponibilidad de la vida individual es justificable también en términos no teológicos, por ejemplo, en el mundo clásico cuando se hace referencia a los deberes en comparación con la comunidad humana (Aristóteles), ${ }^{6}$ o, en el mundo moderno, cuando se hace referencia a los deberes que cada individuo tiene principalmente en comparación consigo mismo (Kant); ${ }^{7}$ pero este género de argumentaciones, si pueden tener una congruencia (no pretendemos discutirlo aquí) cuando se refieren al suicidio son menos, sin embargo, no es así cuando se refieren a la eutanasia es por demás significativo que Kant utilice el caso de un enfermo incurable que se mata para no causar daño a los demás con su enfermedad sin que diga que esta acción sea inmoral.

Así, se admite (aunque no conceda) que el suicidio sea moralmente reprobable, porque comporta la más radical afirmación de la propia individualidad contra los otros o contra el principio de humanidad que kantianamente es interno a cada hombre, se deberá entonces reconocer que no se puede configurar el caso de la eutanasia en estos términos. Aquí la muerte está, por decirlo de algún modo, ya decidida por un mal incurable y el enfermo terminal solamente solicita llevar a cabo un proceso irreversible que ya se encuentra en curso. No sería un acto "solipsista" contra la vida; sino una humilde y apremiante solicitud de un enfermo que sufre sin esperanza de anticipar un acontecimiento que, si no fuera porque es naturalmente inminente, él estaría muy lejano de quererlo.

Su decisión de morir está subordinada a una situación que desea, en la cual la muerte está ya objetivamente trazada. Si el enfermo elige morir no es, tal vez, sólo a causa de los dolores insoportables, sino porque también desea morir con dignidad, sabiendo que probablemente será intubado,

6 Aristóteles, Etica Nicomachea, V, 11, 1138, traducción de A. Plebe, Bari, Laterza, 1973, pp. 136-138 (Opere, vol. 7).

7 Kant, I., La metafisica dei costumi, parte II: Principi metafisici della dottrina della virtù (I. Elementi dell'etica, parte I, lib. I, cap. I, 6), traducción de Di G. Vidari, Bari, Laterza, 1973, pp. 278 y 279. 
que se le aplicarán sedantes que enturbiarán sus sentidos, el intelecto y que lo llevarán a un estado de inconsciencia que puede durar poco o mucho. Su decisión de morir hoy aún es lúcida, no es una decisión en contra de la vida sino contra aquella muerte que siente lesiva a su dignidad de hombre.

Así, un enfermo en fase terminal puede pensar que, no obstante todo, debe vivir, por ejemplo, porque para sus familiares su repentina pérdida podría significar un inmenso dolor y por esta razón rechaza la idea de morir. La responsabilidad que él tiene respecto de los otros podría limitar su derecho de terminar con su vida. Por otro lado también puede pensar que la evolución de su enfermedad no solamente sea tormentosa para él, sino que también para aquellos que le son más cercanos, que su mal no solamente lo esta destruyendo a él, sino que también poco a poco a sus seres queridos. Si existe un deber moral de vivir por lo demás, se deberá entonces reconocer, como ha sostenido Hans Jonas, también existe un derecho a morir por ellos. ${ }^{8}$

$\mathrm{El}$ enfermo terminal se encuentra en condiciones deplorables por lo que no se le podrá negar la elección entre el deber de vivir y el derecho de morir, tal elección es justificable bajo el perfil ético. Su deber de vivir no se puede empujar hasta al punto de anular su derecho de morir. Todas las reservas que limitan desde el punto de vista ético su derecho al suicidio (prescindiendo del punto de vista religioso) se derrumban cuando se está en presencia de una enfermedad incurable que le provocará la muerte. Aquí lo decisivo no es tanto la intención del sujeto (lo que lo empuja a querer la muerte), sino la objetiva situación de necesidad en la cual se inserta su decisión de morir. Se podrá discutir si el suicidio es siempre éticamente justificable, sin embargo, debemos reconocer que lo es, al menos en este caso. Entonces hemos alcanzado un primer elemento: un enfermo terminal,

8 Cfr. Jonas, H., “Tecniche di differimento della morte e il diritto di morire”, en Jonas, H., Tecnica, medicina ed etica. Prassi del principio responsabilità, Paolo Becchi (ed.), Turín, Einaudi, 1992, pp. 185-205 (189 y 190). 
que considera su vida tan insoportable al grado de quitársela, no comete una acción inmoral.

Parece a primera vista que se podría resolver así el problema de la eutanasia. Si el individuo tiene, en aquellas circunstancias, un derecho a quitarse la vida, debería también tener un derecho a ser ayudado, a causa de las condiciones en las que se encuentra, si no está en grado de hacerlo por sí solo. En este caso, sin embargo, las cosas son más complejas, su voluntad de morir implica comprometer a otros que se convierten en sus cómplices en el momento en que facilitan el suicido y que en el caso extremo son ellos quienes realizan la voluntad del enfermo terminal. En la valoración de la eutanasia no podemos no tomar en cuenta este aspecto. Es justamente aquí en donde surgen las dificultades: ¿a quién le corresponde ejecutar la eutanasia? Entre los partidarios de la eutanasia la respuesta a esta pregunta es del todo obvia: es el médico quien ejecutará este acto extremo en su paciente. Pero ¿es éticamente lícito que se empuje al médico a tanto, no nos arriesgamos a dejarle una libertad de acción siempre más ilimitada y no fácilmente controlable?

Bajo el perfil de los riesgos sociales nos parece algo peligroso el hecho de que la muerte la decida, sistemáticamente, y esté bajo la tutela de la clase médica. Los médicos una vez habituados a considerar como normal routine de trabajo la aplicación de la eutanasia, la practicarían más seguido y se corre el riesgo de que para respetar la elección inmediata de algunos pacientes que pidan morir se coloque en peligro la autonomía de muchos otros. Es inevitable que en tal modo aumente el poder de decisión discrecional del médico en detrimento de la relación de confianza, que es fundamental, entre el médico y paciente. Para impedir que el médico pueda matar a sus pacientes conscientes debería entonces existir una medio de defensa en contra de tal poder.

No solamente sobre las consecuencias negativas que se podrían desarrollar con la práctica de la eutanasia y respecto de la conducta del médico en la que nos gustaría in- 
sistir, ${ }^{9}$ se nos podría replicar que ponemos atención sobre efectos perversos que podrían ser superados con controles adecuados. Sin embargo, aún queda deshacer el nudo ético: ¿es lícito que se orille al médico a tanto?, ¿puede considerarse a la eutanasia activa entre los deberes de su profesión?

El médico puede valorar la incidencia de una terapia de frente a una situación definitivamente comprometida $\mathrm{y}$ también determinar su interrupción, puede con la intención de aliviar el dolor de su paciente acelerar el recorrido infausto de su enfermedad, así como suspender el uso de los instrumentos gracias a los cuales el enfermo es sostenido artificialmente con vida; pero entre sus competencias no se podrá incluir la de matar con una inyección letal a su paciente que sufre, aunque este último lo solicite de manera explícita. El médico con los medios que actualmente dispone no debe obligarlo a vivir prolongando inútilmente su sufrimiento, pero tampoco llegar al punto de quitarle la vida. Dicha acción mortal, para el paciente en tales condiciones

9 Para reforzar lo que se ha dicho, véase en relación a la situación de los Estados Unidos de América, cfr. Emanuel, E. J. et al., "The Practice of Euthanasia and Physician-Assisted Suicide in the United States: Adherence to Proposed Safeguards and Effects on Physicians", Journal of the American Medical Association, núm. 280, 1998, pp.1193-1201; Emanuel, E. J., "What is the Great Benefit of Legalizing Euthanasia or Physician-Assisted Suicide", Ethics, núm. 109, 1999, pp. 629-142; Emanuel, E. J. et al., "Attitudes and Desires Related to Euthanasia and Physician-Assisted Suicide Among Terminally I'll Patients and their Caregivers", Journal of the American Medical Association, núm. 284, 2000, pp. 2460-2468. Sobre la situación holandesa $c f r$. Reichlin, M., "L'eutonasia in Olanda: contraddizioni, ambigüita, alternative ", Quando morire? Boietica e diritto nel dibattito sull'eutanasia, Viafora, C. (ed.), Padua, Gregoriana Libreria Editorial, 1996, pp. 173-205. Cfr. también Van der Maas et al., "Eutanasia, Physician Assisted Suicide and Other Medical Practices Involving the End of Life in the Netherlands 1990-1995", New England Journal of Medicine, núm. 335, 1996, pp. 1699-1705; Defanti, C. A., "L'eutanasia in Olanda. A proposito del nuovo Rapporto Van der Maas", Bioetica, 5, 1, 1997, pp. 11-22. Respecto de las intervenciones más recientes del legislativo véase el texto de la ley aprobada por el parlamento holandés el 10 de abril de 2001, esta ley consiente al enfermo terminal de ejercitar el control de la interrupción de la vida y de la asistencia al suicidio y prevé la modificación del código penal y de la ley relativa al tratamiento de los cadáveres: "Legge olandese sull'eutanasia", Bioetica, IX, 2, 2001, pp. 389-395. Para una visión de conjunto de la situación holandesa cfr. Barcaro, R., Dignità della morte, accanimento terapeutico ed eutanasia, Nápoles, E. S. I., 2001, en particular pp. 51-55. 
- como hemos visto- moralmente lícita pone en juego el fin intrínseco de la profesión de médico.

Se podría replicar que lo que hemos dicho presupone una visión tradicional de los deberes del médico ya, de hecho, superada. Desde hace tiempo los límites de esta profesión ${ }^{10}$ se extendieron hasta incluir funciones como la contracepción, la esterilización por motivos no médicos, la interrupción del embarazo, la fecundación artificial, el cambio de sexo, la cirugía estética, se incluyen los antiguos métodos de cura y de alivio del dolor. No pretendemos discutir el aumento de funciones; pero me pregunto, admitiendo que los límites de la medicina no son nítidos y trazados una vez y para siempre ¿no se tiene la idea de un límite cuando se sostiene que sea lícito que el médico mate a petición de sus propios pacientes?

Se podrá de igual forma objetar que el médico presta ya un servicio de muerte cuando interrumpe el embarazo. Sin entrar en la discusión de este problema, nos limitaremos a observar que la muerte de un feto en los primeros meses de vida resalta interrogantes éticas diferentes de aquellas en un enfermo terminal. En la eutanasia activa el médico se encuentra de frente al crudo hecho de matar a su paciente que no tiene esperanza de curarse, que el paciente lo solicite con insistencia no disminuye el acto mortal que el médico está llamado a cumplir.

De frente a una enfermedad incurable que tiene como consecuencia un estado terminal, si bien el médico no puede restituirle la salud a su paciente no tiene porque renunciar a estar a lado de él. Puede estar cerca, aliviando su dolor y esto no significa matarlo. Pero cuando el enfermo le pide que lo haga, en el fondo, transfiere su "ser" que está

10 Sobre la crisis que atraviesa la imagen tradicional de la profesión médica, véase en lengua italiana la antología al cuidado de Cattorini, P. y Mordacci, R., Modelli di medicina. Crisi e attualità dell'idea di professione, Milán, Europa Scienze Umane Editrice, 1993. Sobre el desafío que la profesión médica debe afrontar $c f r$. Callahan, D., False Hopes (1998), La medicina imposible. Le utopie e gli errori della medicina moderna, Milán, Baldini \& Castoldi, 2000 y Veatch, R. M., The Basics of Bioethics, Nueva Yersey, Prentice Hall, Upper Saddle River, 2000, cap. 1, pp. 1-16. 
siendo tratado con dureza por una vida que ya no desea más (pero que no logra interrumpir por sí mismo) a su médico para que se haga cargo. El médico no debe obligar a su paciente a vivir en aquellas condiciones; sin embargo, este último ¿puede pretender que lo mate su médico? y ¿se puede empujar al médico a tanto sin perturbar completamente el objetivo de su profesión?

La idea de que la profesión médica se desarrolla en el tiempo, como en general la idea de la historicidad, no necesariamente debe pensarse en términos relativos. Como el sentido de universalidad no viene a menos si se vive en condiciones particulares, así el sentido de la profesión médica no viene a menos si se ejercita en condiciones contingentes. La esencia no puede que expresarse en la contingencia y es ésta que expresa la esencia. El ser está en el tiempo y el tiempo está en el ser.

Estas consideraciones tienen una cierta importancia filosófica más general, pero creemos que se pueden adaptar a nuestro ámbito específico: aunque puedan variar históricamente las tareas del médico, éste no debe olvidar que en su profesión hay un contenido mínimo, un residuo insuprimible e invariable, que constituye su más íntima esencia. Es precisamente esto lo que impide admitir que el médico se pueda convertir en el asesino de su paciente. ${ }^{11} \mathrm{El}$ resto vale también para otras profesiones: un juez que no fuera imparcial equivocaría el objeto de su profesión, del mismo modo un funcionario corrupto o un deportista dopado.

Si se admite también que la profesión médica no es dato natural, sino un producto cultural como cualquier otra profesión, no disminuye la idea de que aquella sea una profe-

11 Quien más ha insistido en este aspecto es Kass, Leon R., "Neither for Love nor Money: Why Doctors Must Not Kill”, The Public Interest, núm. 94, 1989, pp. 25-46. Cfr. también Pellegrino, E. D., "Doctors Must Not Kill", Journal of Clinical Ethics, 3, 2, 1992, pp. 95-102. Me parece, sin embargo, como intentaré demostrar, que una radical exclusión del médico de la eutanasia no puede ser, o podría serlo si se llega a un acuerdo de negar completamente al enfermo terminal el derecho de morir. Es significativo que Kass llegue a esta conclusión, que aunque coherente con su propuesta, por las razones que adapto, considero aceptable. Cfr. Kass, L. R., “Is There a Right to Die?”, Hastings Center Report, núm. 23, 1, 1993, pp. 34-43. 
sión diversa de las otras. Un individuo no debe necesariamente ser un médico, pero si llegara a serlo no puede confundir su profesión, por ejemplo, con la de un juez, de un funcionario de la administración pública o de abogado. Ya que si vamos con un médico esperamos, obviamente, un trato diverso de aquel que nos puede ofrecer una persona que ejerce otra profesión.

Alguien, en este aspecto, podría reutilizar una vieja objeción que vale la pena discutir. Supongamos, que se sostenga, que es justo destruir varias veces un automóvil pero no que lo lleve a cabo un mecánico. Si la tarea del mecánico es reparar el auto y hacerlo funcionar, si él lo destruyera iría en contra de la esencia de su profesión. Sometiendo a crítica esta argumentación James Rachels ${ }^{12}$ da la siguiente conclusión: ya que consideramos muy extraño e incompatible con la profesión del mecánico demoler un auto, del mismo modo no se ve por qué razones debería sostenerse incompatible con la profesión del médico el matar a un paciente. Se podría de inmediato replicar con otro ejemplo: en una farmacia, aunque actualmente se venden diversos productos, sin embargo, ¿nos quedariamos perplejos si entre estos encontráramos también paquetes de cigarros y botellas de whisky?

El ejemplo adoptado por Rachels nos parece que se pueda leer de manera diversa. Si deseáramos reparar nuestro automóvil seríamos estúpidos si decidiéramos ir con un demoledor, si lo quisiéramos demoler sería poco sensato que fuéramos con alguien que hiciera todo para hacerlo funcionar. En fin, como es justo que el mecánico, usando los instrumentos de los que dispone, busque de cualquier modo que funcione el auto por muy mal que esté, así, igualmente es justo que el médico, utilizando apropiadamente los medios farmacológicos e instrumentos de los que dispone, busque que funcione el cuerpo humano, por muy enfermo que se encuentre. Pero, si esto no fuera posible, en el caso del auto podríamos ir con un demoledor y en el caso de los

12 Rachels, J., La fine della vita. La moralità dell'eutanasia, Milán, Sonda, 1989, pp. 129 y 130. 
hombres ¿a quién podemos recurrir? No hay duda, es difícil encontrar en el caso de los hombres algo similar.

La eutanasia, por lo tanto, se encuentra de frente a un dilema. Por un lado el derecho de morir del enfermo terminal, por otro el deber del médico de no llegar al extremo de transformarse en su verdugo. Si se insiste en lo primero se coloca al médico en una situación de conflicto respecto de los objetivos de su profesión y, de igual forma, se le concede un poder discrecional sobre la muerte socialmente no exenta de riesgos; si se insiste en el segundo se deja en espera un derecho que puede ser justamente reivindicado por el enfermo.

Parecería que no existe una salida: ¿cómo satisfacer la legítima solicitud de morir por parte del enfermo terminal sin que por otro lado se transforme peligrosamente el rol del médico?, ¿deberíamos en este conflicto el mal menor y condenar al paciente a una vida que no desea más, o evitar el asesinato de pacientes por parte de los médicos, y así no transformar el fundamento y el sentido de su profesión y el de su papel social? Se puede, probablemente, salir de este cerco, que condena al enfermo o no ver agotada su legítima solicitud, si se considera a la eutanasia, diversamente de cómo se ha considerado normalmente hasta la fecha, no como un acto que exclusivamente le corresponde al médico. Me pregunto: si el médico no puede matar, ¿puede hacerlo alguien más en su lugar?

Regresemos por un momento al ejemplo del demoledor de automóviles y preguntémonos si no se puede pensar efectivamente en una cosa parecida para los hombres. Así, como aún existe en muchos países el papel de los verdugos, se podría instituir una nueva figura - esta hipótesis provocadora la elabora Robert Veatch- de asistente social encargado de aplicar la eutanasia. ${ }^{13}$ Descuidamos aquí el hecho

13 Crf. Veatch, R. M., Death, Dying and the Biological Revolution, New Haven-Londres, Yale University Press (edición revisada), 1989, p. 63. Véase también Baumrim, el cual considera que la tarea de asistir al paciente terminal, que ha solicitado, después de un exhaustivo examen por parte de la autoridad judicial, pueda ser absuelto por el Right to Die - Societies (Asociación per il Diritto di Morire). 
que se podría considerar como deseable la abolición del verdugo ya que solamente se busca encontrar algo similar para los pacientes terminales.

Este remedio me parece peor del mal que se desea curar: cierto, se salvaría la figura del médico, pero la eutanasia asumiría la semblanza de una ejecución técnica, análoga a la del verdugo, privándola de su auténtico y lacerante significado ético. Digámoslo entonces: ésta es una solución que congela el ánimo en una situación ardiente y trágica. Pero aún no todos los actores han aparecido en escena. Hasta ahora habíamos considerado a la eutanasia partiendo de la relación médico-paciente y la última solución proyectada se pensó para saltar el obstáculo de la ética profesional del médico, no para responder la situación existencial del enfermo terminal que pide morir.

Al inicio de este trabajo mencionamos el hecho de que el problema de la eutanasia si se considera únicamente en su dimensión ética, más allá de sus reflejos sociales ("eutanasia de abandono"), puede configurarse como la decisión consciente y éticamente sostenida de un enfermo terminal, el cual se encuentra en un periodo infeliz de su vida en un contexto afectivo de personas que lo quieren y que lo atienden.

Habitualmente tal contexto es ofrecido por la comunidad familiar, aunque hoy pueden variar los modelos de familia (regresaremos más adelante a este aspecto), pensamos que el amor representa un elemento común en aquellos. No se ha dicho que sea necesario un contexto de este género, ya que es posible que un individuo no tenga una familia propia o bien la tenga pero que no sienta parte de ella. En este caso él no estará completamente solo pero tampoco contará con el afecto de una familia, aunque puede darse que encuentre un amigo fraterno. Son los familiares, los amigos,

Estas asociaciones tienen las mismas funciones asesoramiento y asistencia médica, legal y psicológica, para sus inscritos, en éstas pueden obtener la información necesaria para llevar a cabo el suicidio. Cfr. Baumrin, B., "Physician, Stay Thy Hand!", en Batín, M. P. et al. (eds.), Physician Assisted Suicide. Expanding the Debate, Nueva York, Routledge, 1998, pp. 177-181. 
aquellos que comparten con él la vida y su lento e inexorable fin. Son ellos los sujetos emotivamente involucrados, e incluso, perturbados con en la eventual decisión de morir. Es en este contexto que, quizá, podemos encontrar la clave para responder éticamente el enigma de la eutanasia.

Un ejemplo concreto ilustrará mejor lo que pretendemos decir. El marido que ha amado a su esposa por tantos años, que ha compartido con ella momentos de intensa alegría, que conoce el tormento que vive su mujer al padecer una enfermedad incurable no podrá más que compartir con ella su decisión voluntaria de poner fin a su vida y darle la muerte que implora como gesto supremo de amor. El hijo que tiene enfrente a la madre que le ha dado la vida y ahora, consumada y vencida por el dolor, le implora que la ayude a morir no podrá no llevar a cabo esta tarea. Y la madre que le ha dado la vida no podrá, entonces, no quitársela cuando ella se convierta en algo insoportable al grado de empujarlo a llevar a cabo una brusca despedida al prolongar una existencia dolorosa. O también el compañero de tantas batallas que escucha la solicitud del amigo fraterno no podrá dejar de llevar a cabo el gesto extremo de solidaridad que con firmeza le pide.

Si la decisión de morir por parte del enfermo es irrevocable como su enfermedad, entonces sólo quien le es más cercano, quien más que nadie ha deseado su vida, podrá regalarle la muerte. Ahora, en este momento, en este presente que decide un individuo que reconoce de frente a otro el haber sido y el no querer ser. Aquél que pide morir sentirá en el momento de irse la presencia y el afecto más grande de quien lo ayudó a hacerlo, el cual cumplió con una obligación por amor fraterno y de la cual no podía deshacerse. No se trata de una acción de routine, como sería en el caso en que fuera institucionalizada médicamente, sino de un acto único e irrepetible para la persona que lo lleva a cabo: el último testimonio de amor o de profunda amistad a la persona amada, ya que la vida de éste solamente es un cúmulo de creciente sufrimiento. 
No encontramos en esta acción nada de moralmente reprobable, ni mucho menos condenable bajo el perfil jurídico. Aunque si bien, no todo puede ser escrito en códigos o leyes. De un código solamente pueden ser eliminados o modificados aquellos artículos y fracciones que prevean e impongan penas para aquellos que hayan aplicado la eutanasia por las razones y en el modo que lo describimos. ${ }^{14} \mathrm{Es}$ una ley que nos empuja a cumplir esta acción, no diversa de aquella que orilla a Antígona a dar justa sepultura a su hermano muerto.

Regresamos a la tragedia de Sófocles: aquí me gustaría subrayar un aspecto que quizá no se le ha dado importancia como lo amerita. Defendiendo el rito fúnebre que ella llevó a cabo cuando afirma:

Sin embargo, yo te rendí justamente honores, las personas sensatas no censuraron mis cuidados. De hecho, no, porque, ni si hubiese tenido hijos, ni si hubiera sido el cadáver de mi marido que se corrompe, nunca hubiera asumido este oficio en contra de los valores de los ciudadanos. ¿Y con qué fuerza y en virtud de que ley lo afirmo? Muerto mi marido, habría podido tener otro; y así un hijo de este hombre, si aquél me hubiera faltado. Pero ahora que mi madre y que mi padre están en el fondo de Hades, es imposible que tenga otro hermano. ${ }^{15}$

Antígona llega a sacrificar su vida y la esperanza de su propia familia por la fidelidad al vínculo de la estirpe a la que pertenece. Pero esto es sólo un aspecto. Aquello que surge directamente del párrafo citado, que sin embargo me parece debe ser objeto de una lectura más profunda. Antígona rinde honores a su hermano muerto porque ya no lo tendrá más, es consciente del hecho de que tal relación es

14 Respecto del ámbito penal me limito a señalar dos contribuciones de Luciano Eusebi (Il diritto penale di fronte alla malatia) y Luigi Stortini (Reflessioni in tema di eutanasia), en Fioravanti, L. (ed.), La tutela penale della persona. Nuove frontiere, difficili equilibri, Milán, Giuffrè, 2001, pp.119-142 (Eusebi), pp. 143-155 (Stortini).

15 Cfr. Sófocles, "Antigone”, en Cantarella, R. (ed.), Tragici greci, Milán, A. Mondadori, 1977, p. 321. 
única e irrepetible: una relación que comprende los vínculos de consanguinidad, pero que ahí supera una visión más amplia. Antígona es amiga de su hermano, y esta fuerza de fraterna amistad es la que la confronta consigo misma. La situación, cierto, no tiene relación directa con la que se describió sobre la eutanasia (pero vale de igual forma recordar que para honrar al hermano muerto, Antígona muere porque se suicida y este suicidio no involucra a los otros dos), pero hemos querido mencionarlo porque el modo en el cual Antígona describe su relación con su hermano corresponde perfectamente con aquella relación única e irrepetible en la cual un individuo se encuentra con un pariente o con un amigo que sufre, que ha perdido toda esperanza, y le pide morir en paz.

Se podría replicar: si es verdad que los familiares, o quienes se está ligado por vínculos de fraterna amistad con el enfermo terminal, son los que puede actuar con sincero y auténtico compromiso y pensando exclusivamente en el interés de sus seres queridos, así es igualmente verdadero que ellos pueden ser los más beneficiados (en términos económicos, y también respecto perfil psicológico) con su muerte. Es exactamente aquí en donde los órganos jurisdiccionales deberían intervenir y verificar que el acto de la muerte sea llevado a cabo con el único objeto de respetar la voluntad de un enfermo terminal y de castigar eventuales abusos. la protección jurídica me parece suficiente para impedir que la trágica elección de la eutanasia, llena de fuertes emociones entre quien se está yendo y aún está, se convierta en una erogación de un servicio, como tantos otros, por parte de la institución sanitaria local. Lo que proponemos es una eutanasia médicamente institucionalizada, que sería una eutanasia en la que en la medida de lo posible se realice en el ámbito de la familia.

Bien entendido esto, nuestra conclusión no tiene por objeto excluir por completo al médico de la eutanasia. El aspecto decisivo es más bien que la eutanasia se perciba como un problema que no puede encontrar una solución 
adecuada al interior de la relación médico-paciente. De lo demás, la verificación de la "prognosis" infausta es obviamente competencia del médico. Destacamos la importancia del papel del médico puesto que - hay que decirlo - con un poco de voluntad cualquiera podría estar cerca sin muchas dificultades; sin embargo, se requiere de sus conocimientos profesionales ya que éste es quien determina el fármaco exacto y la dosis correcta que se debe aplicar para que la muerte no implique un dolor físico. En este caso la ayuda del médico termina con impedir una muerte dolorosa para quien ha decidido morir y superar el eventual y sucesivo trauma de quien a llevado a cabo el acto de aplicar la eutanasia. Del mismo modo será el médico quien verificará que al realizarse el acto no se hubieran violado los derechos del enfermo terminal.

Es por lo anterior que el médico de cualquier modo se encuentra en el drama de la eutanasia, pero lo importante es que lo haga como simple acompañante. ${ }^{16}$ Los verdaderos protagonistas del drama son otros: la persona que sufre, que sin posibilidad de cura quiere morir y quien - ya sea familiar o amigo - se siente capaz de llevar consigo el peso de esta extrema decisión. Bajo esta perspectiva mutan no solamente los papeles de los protagonistas, también los lugares del drama. Si el centro de atención se mueve de la relación médico-paciente a la esfera íntima de las relaciones familiares-amistad, entonces la eutanasia deberá ser ajena a las instituciones hospitalarias, deberá provenir del ámbito privado, de la propia casa o de cualquier lugar de la atmósfera familiar.

Puede parecer que se deja caer sobre los familiares un peso demasiado grande e insoportable, como es el de matar a un familiar. Cierto, porque consideramos que matar sea - como normalmente, en efecto, es- malo, encontramos

16 Ésta es mi respuesta a las críticas, para mí muy estimulantes, que da F. Toscani a un artículo reciente que presenté sobre el tema. $C f r$. Toscani, F., "Eutanasia, medicina: un commento all articolo de P. Becchi”, Bioetica, vol. III, núm. 3, 1995, pp. 444-450. 
una instintiva repulsión al pensar en matar a un ser querido, aunque sea éste quien implora que se cumpla tal acción. Pero si es así ¿por qué el médico que tiene la tarea de cuidar, aliviar el sufrimiento y posiblemente curar, debería matar?

El problema de la eutanasia no se resuelve ampliando en modo injusto las funciones del médico, sino transformando en modo responsable nuestro comportamiento respecto de la muerte. Nadie puede desear para sí o para los demás una muerte dolorosa que poco a poco nos convierta en imbéciles y nos someta a estar recluidos en la caricatura de nosotros mismos, cuando aprendamos a considerar que la decisión de morir de uno de nuestros familiares que se encuentra atormentado por el dolor y sin más esperanza de sanar sea moralmente lícita, entonces podremos comenzar a considerar la ayuda que aquéllos nos piden e incluso "el acto ejecutivo extremo" como un gesto de piedad al cual no deberemos negarnos.

Hemos buscado explicar por qué el contexto familiar y/o de amistad se convierte en decisivo al intentar ofrecer una solución éticamente sostenible al problema de la eutanasia. Quisiéramos mostrar que en alguna medida el mismo contexto es relevante también para afrontar en modo adecuado este controvertido tema (también a la luz de la más reciente ley italiana) de la extracción de órganos del cadáver. Afrontaremos este tema a partir de dos premisas: en la primera asumiremos que la extracción de órganos viene efectivamente ejecutada en un cadáver, en la segunda contestaremos exactamente este punto, que generalmente se considera obvio.

El primer cuestionamiento que presentamos es el siguiente: si admitimos que se trata de un cadáver ¿en qué condiciones podemos suponer éticamente sostenible la utilización de sus órganos para prolongar la vida de otras personas? El segundo cuestionamiento es sin duda más inquietante: se debe reconocer que la extracción de órganos no siempre se verifica en cuerpos que para todos los efectos 
sean considerados cadáveres en este caso ¿es razonablemente defendible la tesis de la licitud ética de los trasplantes?

\section{LINEAMIENTOS DE UNA ÉTICA CADAVÉRICA}

Partimos del primer cuestionamiento. Un cadáver es el cuerpo de un hombre ya sin vida, que en un cierto lapso de tiempo se encontrará en grado de putrefacción, tal cuerpo sin vida no es más una persona, es de cualquier modo el despojo mortal de ésta. Por esta razón creemos que incluso los restos en sí, en cuanto permanece por siempre la proyección más de la vida que fue, tiene derecho a que sea tratado con respeto. Lo que queremos decir es que no sólo las personas, sino que también los cadáveres tienen dignidad. No pretendo, sin embargo, insistir en este punto.

Deberemos por lo menos admitir que un comportamiento de respeto hacia los restos sea deducible del valor afectivo del cual éstos son portadores. Honrar la memoria de los difuntos regresa a aquellas formas de respeto en las que los hombres desde siempre se reconocen recíprocamente. ${ }^{17}$ En relación con el cadáver podemos decir que el respeto proviene del recuerdo que éste trae consigo de cuando estaba vivo. Este recuerdo no es del difunto que al estar muerto, obviamente, no puede recordar nada; sino de aquellos que han compartido con él su vida. Generalmente se trata de los familiares y amigos más queridos, aunque esto no debe entenderse como exclusivo, podría por ejemplo tratarse de la muerte de un líder en el cual muchos se reconozcan y que tal pérdida la sientan muchas más personas. Pero también en este caso ninguno podrá decir que los restos sean un objeto sobre todo de la memoria de sus familiares, del afecto que la rodea a ésta y de su piedad.

17 Cfr. Hofmann, H., "Die versprochene Menschenwürde", Archiv des öffentliches Recht, 118, 1993, pp. 353-377 (375). Cfr. también Seelmann, K., "Organtransplantation - die strafrechtlichen Grundlangenprobleme”, en Brudermüller, G. y Seelmann, K. (eds.), Organtransplantation, Würzburg, Königshausen \& Neumann, 2000, pp. 29-42 (33). 
Si se mira bien, con la muerte se presenta una situación que se especula totalmente contraria al nacimiento. Si al momento del nacimiento (y en realidad antes) son los padres quienes cuidan de los hijos, al final de la vida (y también después) son los hijos los que frecuentemente cuidan de sus padres. Esta es la naturaleza de las cosas. Los hijos restituyen en tal modo los cuidados amorosos que sus padres les dieron cuando eran pequeños. Alguna vez el peso de la balanza puede ladearse más de un lado que del otro, pero en general esto que se verifica es un justo equilibrio.

Desde el momento en que un individuo nace se inserta en una familia y su muerte se efectúa en un contexto que permanece antes que nada familiar. Así, cuando un individuo crece y se convierte en una persona adulta puede decidir si permanece para toda la vida soltero, pero si estuviera en este caso no se encontraría completamente solo pues tendrá o habrá tenido un amigo, una persona en la que confiaba, y con la cual sostenía una relación más íntima que con otras. La idea de un individuo sin ninguna relación de pertenencia es - diría Carlos Marx - una de las grandes robinsonadas del siglo XVIII. Aunque posible al menos como hipótesis puede de igual forma aquí abandonarse, en relación con esto se puede decir que si una persona - por decisión o por necesidad- permaneció efectivamente sola cuando estaba viva, su soledad debe respetarse también cuando esté muerta. Un muerto deja un vacío en un espacio que él ocupa con los demás, y de cuanto a cabamos de decir debería resultar claro que este espacio se encuentra antes que nada al interior de la familia.

En nuestro discurso (también en el relacionado a la eutanasia) hemos dado tanta importancia a la familia porque quisiera precisar aquí que somos conscientes de que hoy se ha transformado: ${ }^{18}$ un hombre (obviamente el mismo dis-

18 Contrariamente a quien había previsto la inevitable "muerte" de la familia, ésta demuestra hoy una renovada vitalidad. Desde un punto de vista sociológico tal hecho ha sido bien destacado por Donati, P., La famiglia nella società relazionale, Nuove reti e nuove regole, Milán, F. Angeli, 1994. Desde un punto de vista jurídi- 
curso se puede hacer para la mujer) aunque se haya casado y divorciado dos o tres veces en su vida y tal vez haya tenido hijos con diversas mujeres, o bien convive con otro hombre. Un hombre y una mujer pueden decidir tener un niño y este niño tener, por ejemplo, dos madres. Aquella que lo trajo en el vientre y que parió, y aquella biológica che ha contribuido solamente con su huevo, tal vez tampoco fecundado por el semen del marido, sino con el de otra persona. Alguien podría objetar que todo esto se encuentra muy lejos de nuestra idea de familia. Prescindiremos aquí de cualquier evaluación ética y diremos simplemente que en la mejor de las hipótesis (o peor, según sea el punto de vista) aquel niño tendrá dos madres y dos padres que se ocuparán de él.

Esta nueva situación no modifica, sin embargo, el asunto principal y del que partimos. Por mucho que haya cambiado nuestro modo de entender la familia y por múltiples que puedan ser actualmente los modelos de ésta no se puede negar que tanto el nacimiento como la muerte de un individuo sean eventos que se relacionan en primer lugar con un núcleo de personas más reducido, que generalmente se identifica antes que nada con un núcleo familiar (aunque también existen vínculos con la sociedad y el Estado), en el que el recién nacido entra en contacto y del cual el muerto se despide definitivamente.

Un individuo cuando nace viene a ocupar un espacio en el que otros, normalmente sus padres, ya se encuentran; el mismo recién nacido al crecer se convertirá en un individuo adulto, envejecerá y morirá dejando un vacío en un contexto diverso de aquél en el que nació. Así como el recién nacido se encuentra al cuidado de sus padres y éstos son los

co me limitaré a citar la amplia colección de estudios al cuidado de Spallaro, M. R., Famiglia e servizi. Il minore, le famiglia e la dinamiche giudiziarie, Milán, Giuffrè, 2001. Bajo el perfil filosófico merecería una discusión profunda y crítica: D’Agostino, F., Una filosofia della famiglia, Milán, Giuffrè, 1999; también resultan estimulantes las recientes investigaciones de Cimmino, L. y Cuomo, E., Simbolica e normatività della copia tra etica del comportamento e principi costitutivi, Nápoles, Guida, 2001. 
responsables de su hijo, así son llamados a hacerse cargo del cadáver, las personas (generalmente los familiares) que hayan convivido con él. Se les llama para hacerse cargo del cadáver, del funeral y de la sepultura. Así como el recién nacido es antes que nada de sus padres, así el cadáver es antes que nada de aquellos familiares que permanecen cerca de él durante su recorrido hacia la muerte.

Con él, de hecho, se va también una parte de ellos, como se muestra en lo que psicológicamente viene llamado el proceso de elaboración del luto relacionado con la pérdida de un ser querido. Así como los padres deben ocuparse de sus recién nacidos, los familiares deben ocuparse de sus muertos. Esta reflexión puede parecer obvia, sin embargo es más importante de lo que se pueda imaginar. Si ésta se acepta, desde un punto de vista ético, implica una primera conclusión de mucha importancia. Cualquier radical exclusión de la familia del destino de sus muertos es injusta, cualquier radical intromisión del Estado en esta situación es ilegítima. Antígona tenía razón al querer sepultar el cuerpo de sus hermanos y Creonte era un tirano al querérselo impedir.

Es cierto, existe la clásica contraposición entre una ley positiva injusta (la de Creonte) y el derecho natural que empuja a Antígona a oponerse a ella. Pero existe otro aspecto sobre el cual vale la pena detenerse. Creonte pretende reducir las relaciones humanas a la esfera de la política, en un modo un tanto unilateral invadir incluso el reino de los muertos, y Antígona se opone a tal reducción, reivindicando (al menos para los muertos) un espacio autónomo de la politica.

El conflicto es en el fondo de carácter político puesto que quiere subordinar a sí cualquier punto de vista y no acepta esta subordinación. Creonte decide políticamente (schmittianamente querría decir) la diferencia entre los dos hermanos muertos de Antígona: por un lado que Eteocles, salvador de Tebas, fuera sepultado con todos los honores, y por otro que el cadáver de Polinices permaneciera sin sepultura, puesto que "el enemigo no es nunca amigo, ni siquiera 
muerto". Pero para Antígona la politicidad del desencuentro que ha confrontado en vida a los dos hermanos no cuenta para nada después de su muerte: "la ley de Hade iguala a todos". ${ }^{19}$ Los dos hermanos ya desde el nacimiento en cierto sentido eran iguales porque nacieron del mismo padre y de la misma madre; pero fueron las circunstancias políticas las que los hicieron diversos. Uno amigo de Tebas y el otro enemigo. Sin embargo, con la muerte regresaron a ser iguales. El mensaje es claro, la política se ocupa de los vivos y deja en paz a los muertos, deja que de éstos se ocupen aquellos que están ligados por un vínculo de otra naturaleza, más profundo y diferente al de la política.

Esto vale hoy como entonces. Sin embargo, para Antígona era impensable que su hermano tal vez hubiera tenido ideas diversas a las de ella respecto a la sepultura y al trasplante de órganos. Es así como pasamos a los problemas de nuestros días, pero no olvidando las enseñanzas del mito clásico. ${ }^{20}$

Si un individuo que fue bautizado y en el transcurso de su vida ha renunciado a seguir los ritos tradicionales de la Iglesia Católica y también al final de sus días no ha demostrado la mínima señal de conversión, renunciando a cualquier señal de apoyo religioso, nos preguntariamos ¿qué sentido tendría en este caso un funeral religioso?, para él ninguno, más bien probablemente lo consideraría contrario a sus principios. Sin embargo, si es verdad lo que acabamos de escribir, es decir, que el cadáver está estrechamente ligado al afecto de sus seres queridos, se deberá admitir que éstos sean de algún modo tomados en cuenta.

19 Sófocles, op. cit., nota 15, pp. 307 y 308. Para una lectura que considera en sintonía con la que se ha proyectado aquí cfr. Zanetti, G., Amicizia, felicità, diritto. Due argomenti sul perfezionismo giuridico, Roma, Carocci, 1998, pp. 100-106.

20 Eugenio Lecaldano tiene una opinión diferente, sostiene que actualmente es necesario equilibrar los deberes que tenemos respecto de nuestros difuntos con los deberes que tenemos respecto de las personas que pueden salvarse gracias a los órganos de nuestros familiares. En las páginas siguientes busco ofrecer un posible modelo alternativo del que ha presentado Lecaldano. Cfr. Lecaldano, E., Bioetica. Le scelte morali, Roma-Bari, Laterza, 1999, pp. 282-317. 
Parecería del todo aceptable sostener que los familiares deben ser respetuosos de la última voluntad de su familiar. Sea la explícitamente expresada o también implícitamente con su comportamiento cuando estaba vivo. Sin embargo, no se puede excluir que el difunto tenga esposa y/o hijos para los cuales el apoyo de la religión en un momento tan triste sea de gran ayuda. El derecho del muerto a que sea respetada su voluntad expresada cuando estaba vivo puede entrar en conflicto con el derecho de los familiares a manifestarse en determinada manera respecto de la forma en que llevan su luto.

Se nos podría objetar que hemos planteado el problema en términos totalmente equivocados. Por un lado, el derecho es de los vivos y el muerto, estando muerto, no tiene más algún derecho y por el otro los familiares tienen obligaciones respecto de los restos de su pariente, pero no pueden alegar en esto ningún derecho. Estas objeciones son mucho menos convincentes de cuanto parecieran a primera vista.

Un cadáver no es más una persona y admitimos (no pretendemos afrontar este punto controvertido) ${ }^{21}$ que solamente las personas son titulares de derechos; sin embargo, sostenemos lícito que una persona in vitam pueda disponer, al menos dentro de ciertos límites, de sus bienes materiales. No se ve entonces porque razones una persona no debería tener algún poder de disposición sobre esto y de lo que ha sido suyo durante su vida. Su cuerpo. En definitiva, no podemos no reconocer un derecho de la persona a dejar disposiciones sobre sus propios restos.

21 En una perspectiva ecocéntrica se abre el problema de los derechos de la naturaleza. Entre la ya amplia y valiosa literatura me limitaré a recordar: Stone, C. D., Should Trees Have Standing? Toward Legal Rights for Natural Objects, Los Altos, Kaufman, 1974 (que pueden considerarse como clásicos de este género) y Bosselmann, Im Namen der Natur. Der Weg zum ökologischen Rechtsstaat, Darmstadt, Wissenschaftliche Buchgesellschaft, 1992. En traducción italiana, para una discusión del tema véanse dos recientes antologías: Tallacchini, M. (ed.), Ethiche della Terra. Antalogia di filosofia del ambiente, Milán, Vita e Pensiero, 1998 y Dellavalle, S. (ed. e introducción), Per un agire ecologico. Percorso di lettura attraverso le proposte dell'etica ambientalista, Milán, Baldini \& Castoldi, 1998. 
También la idea de que los familiares tengan sólo obligaciones en relación con sus difuntos es menos conveniente de cuanto pareciera. Antígona se sentía obligada a dar una justa sepultura a su hermano muerto, pero tal obligación, si no para sus tiempos, por lo menos para nosotros, puede configurarse en términos de derechos. En este contexto, lo que se encuentra en juego no es tanto el derecho natural de resistir a la ley positiva injusta, es algo diverso, más subjetivo. Cuando decimos que es fácilmente explicable si reflexionamos nuevamente sobre el ejemplo del recién nacido nos referimos a lo siguiente: cierto, los padres tienen obligaciones, deberes, respecto de éste; pero ¿sólo tienen obligaciones o, tal vez, también tienen el derecho de ver crecer a su hijo y de oponerse si se presentara cualquier intento de robarlo? Entonces, algo similar se podría decir para el cadáver.

Los familiares tienen obligaciones respecto de sus difuntos (tales tradiciones consistían en proveer el funeral y la sepultura), pero ¿no tienen también el derecho del luto provocado por tal pérdida? Tal derecho responde a aquel sentimiento de piedad en relación con nuestros difuntos, que en tanto formalizado en los ritos religiosos, es un patrimonio de la civilización. Es significativo que tal sentimiento de piedad encuentre incluso, en el nuestro como en otros ordenamientos, una específica tutela jurídica. Pero concentrémonos aquí en el perfil ético.

$\mathrm{El}$ primer problema ético que respecto del cadáver se destaca se presenta cuando subsiste una discrepancia entre la voluntad expresada en vida del ahora difunto respecto de sus propios restos y de la voluntad de sus familiares en relación con los restos. ¿Es posible equilibrar la una con la otra? o, en otros términos, ¿en qué punto éticamente sostenible puede extenderse la voluntad de los familiares respecto del ahora difunto que se ha ido para siempre? No podemos desatar este nudo si no consideramos un poco más de cerca la relación que existe entre un individuo y su familia.

Es verdad que un individuo nace y vive sobre todo el interior de un núcleo familiar; sin embargo, cuando crece afir- 
ma cada vez más una propia individualidad hasta que se convierte en una persona adulta autónoma y responsable. No son sus familiares sino él mismo el responsable de sus acciones. Históricamente no siempre ha sido así, pero es indiscutible que este trato individualista es distintivo, grosso modo de Hobbes en adelante, de la modernidad, que por lo menos en Occidente se ha constituido con el primado del individuo. No sabemos hasta que punto esta consideración de nuestra parte pueda extenderse más allá de Occidente; sin embargo, se trata de un aspecto que aquí podemos no considerar, ${ }^{22}$ así como podemos evitar discutir si un determinado postulado individualista tenga todavía un sentido.

No obstante el aumento de las molestias producto de las confrontaciones con la modernidad y el debilitamiento que el primado del individuo pudo adquirir rápidamente, asumiremos simplemente que algún sentido tiene todavía. Es sorprendente que en un tiempo en el que se pretender privatizar todo (o casi) haya quien - como John Harris- sostiene la necesidad de estatalizar los cadáveres. 23

En realidad ya habíamos visto que precisamente el Estado no tenía ningún derecho sobre los cadáveres y que si acaso es la familia la que eventualmente tiene el poder de hacer algo al respecto. Pero si adoptamos el punto de vista individualista, al cual hicimos referencia, es evidente que también la voluntad de los familiares debe en última instancia ser subordinada a la posible voluntad contrastante de uno de sus miembros. Cuando estamos en presencia de una declaración explícita de voluntad de un individuo respecto de sí mismo en el tiempo sucesivo a su muerte es

22 Sobre el tema recordamos un volumen que recoge los trabajos del XXI Congresso Nazionale della Società Italiana di Filosofia Giuridica e Política (Salerno-Ravello, 7-10 de octubrede 1998), Catania, A. y Lombardi Vallauri, L. (eds.), Concezioni del diritto e diritti umani. Confronti Oriente-Occidente, Nápoles, ESI, 2000.

23 Harris, J., Wonderwoman e Superman. Manipolazione genetica e futuro dell'uomo, Milán, Baldini \& Castoldi, 1997, pp. 165 y ss. Se recuerda aquí que en tiempos no recientes la perspectiva de la "nacionalización" de los cadáveres en función de la promoción de los trasplantes era sostenida en Italia por juristas reconocidos. 
ésta la que se deberá atender, aunque sea diversa a la de los familiares.

Cierto, el sujeto decidido a hacer respetar también en este caso su voluntad espera que cuando llegue el momento se active y se haga manifiesta. Si él deseaba un funeral particular en lugar de la sepultura, la cremación, o, si era su intención donar sus órganos sabiendo que con una o más de estas decisiones iba en contra de la de sus familiares él debería explicitar su voluntad en un "tipo" de testamento, haciendo referencia a estos aspectos que lo colocan en contraposición de sus familiares. Eventualmente también podría conferir a un mandatario el encargo, cuando llegara el momento de llevar a cabo el funeral y la sepultura según determinadas modalidades y de decidir por él mismo si da su consentimiento para la extracción de los órganos.

Estas declaraciones de voluntad aunque sean contrastantes con las de la familia serán respetadas como si la persona aún estuviera viva. Nadie puede obligar a otra persona a donar su sangre, pero si su voluntad fue que se hiciera, su mujer o sus hijos no podrán contrariar esta decisión; algo análogo debería valer pera la extracción de los órganos de su cadáver. También en este caso es la voluntad del individuo en la que se debe pensar más que en otra cosa.

Esto no puede llegar al grado de impedir que sus seres queridos, en ausencia de los restos, se encuentren en la Iglesia para recordarlo juntos y orar por él, o lleven flores y prendan veladoras sobre su tumba, aunque el individuo no deseara este tipo de expresiones. Para él el "sueño de la muerte" no será así menos duro, puede serlo en cambio para aquellos que también en este modo, reconfortados por la religión, logren llevar mejor su propio luto. Y esto sin duda es su derecho.

Por otro lado —admitámoslo- un simbolismo laico que puede cumplir la misma función del religioso no existe actualmente y no es fácil inventarlo de hoy a mañana. Todo esto tiene que ver con los que se quedan y si alguno de sus actos exteriores pueden ser diferentes a los que pensaba el 
difunto es lícito que así ocurra. Aquello que no debe ocurrir es que tales actos se refieran directamente a sus órganos. También el cuerpo después de la muerte, con todos sus órganos, es suyo y de nadie más, ni siquiera las personas que más están en contacto con el cuerpo, mirándolo, tocándolo, amándolo, tienen el derecho de disponer en modo diferente de aquél que el difunto cuando estaba vivo había previsto.

Así, hemos alcanzado un primer punto en relación con el problema de los trasplantes: la extracción de órganos del cadáver es éticamente sostenible cuando se efectúe con el explícito consenso del donador con base en una decisión consciente a la que nadie tiene el derecho de oponerse. Pero ¿siempre es necesario contar con el consentimiento explícito a modo que se pueda proceder a la extracción de los órganos?

¿Qué hacer en el caso de que el sujeto no haya dejado alguna disposición al respecto? Nos encontramos así, de frente a una de las cruces de nuestro tiempo y a los más variados mecanismos ideados para saltar este obstáculo (la falta de una favorable y explícita declaración de voluntad) de la extracción de órganos. No pretendemos discutirlos aquí. ${ }^{24}$ Me limitaré a adelantar una propuesta que me parece puede surgir coherentemente de lo que se ha dicho hasta ahora. Ésta se dirige en sentido totalmente contrario a aquélla adoptada por el legislador italiano en la más reciente ley sobre los trasplantes. ${ }^{25}$

Para responder a la pregunta que he planteado debo, sin embargo, partir de una consideración más general que tiene que ver con la forma en la que nos relacionamos con la muerte. La muerte es un argumento que por lo general, probablemente porque se originan supersticiones, no se ha-

24 Otro aspecto, que no tomé en consideración, es el de la comercialización de los órganos, que no obstante se encuentra penado en diversas legislaciones es objeto de discusión en el ámbito bioético. Cfr. infra, pp. 149-164.

25 Para una más acabada discusión de los diversos aspectos de la reciente disciplina jurídica cfr. varios autores, La disciplina jurídica de los trasplantes. Legge 1o. Aprile 1999, núm. 91, Milán, Giuffrè, 2000. 
bla con agrado. Discutimos cierto, sin dificultad, sobre "el ser para la muerte" en Ser y tiempo de Heidegger o sobre la "demostración de la imposibilidad de vivir" en el Malte de Rilke (el cual, no por si acaso, llegó a proporcionar disposiciones precisas sobre su tumba), o, más banalmente sobre el hecho de que si muere por colocarse o estar en una situación riesgosa, por una dosis de heroína, por una grave enfermedad, como nuevamente sucede en Italia, por manifestarse en la plaza; pero hablar de la propia muerte y más concretamente en relación con el funeral, a la sepultura y, actualmente, también en relación con el eventual destino de los órganos, incomoda a quién habla y probablemente también a quién escucha, y rápidamente buscan desviar el discurso hacia otros argumentos. ${ }^{26}$ Sin embargo, es exactamente el aumento de la necesidad de órganos lo que podría ayudar a superar esta situación. La muerte que en la modernidad parecía excluida de la vida ${ }^{27}$ podría convertirse en objeto de "cambio simbólico" para aquélla, desde el momento en que los muertos donan sus órganos, podrían revelarse como los mejores amigos de los vivos. Es aquí, en donde creo llega el momento de superar la natural dificultad al hablar de ciertas cosas, y el lugar indicado para comenzar a hacerlo es el de la intimidad familiar. Esto por las razones que se han mencionado.

El cadáver es la presencia de una ausencia percibida como tal al interior de la familia. Y es justo que sea exactamente ahí en donde se comience a discutir de aquello que desearíamos se hiciera con nuestro cuerpo una vez que hayamos dejado de vivir. Si esto vale para el funeral, la sepul-

26 De la lectura de las páginas, insuperables, que nos ha dejado Tolstoi, en la Muerte de Iván I'ic; en la sociología también insuperables páginas de Elias, N., La solitudine del morente, Boloña, Il Mulino, 1985. La evolución histórica del comportamiento del hombre occidental frente a la muerte esta documentada por Ariés, P., L'uomo e la morte dal medioevo a oggi, Roma-Bari, Laterza, 1980 y por Vovelle, M., La muerte e l'occidente dal 1300 ai giorni nostri, Bari-Roma, Laterza, 1993. Heidegger ha tomado la contraposición del "Si-mismo" al "Uno-mismo" el trato no auténtico del "se muere" (Essere e tempo, párrafo 51), pero en tal modo, desde mi punto de vista, reduce el tout-court a la inautenticidad de la cotidianidad del existir.

27 Baudrillard, J., Lo scambio simbolico e la morte, Milán Feltrinello, 1992. 
tura o eventualmente la cremación, esto vale con mayor razón para una decisión sin duda emotivamente más comprometedora como la de la donación de los órganos. De la comparación podrá resultar que subsiste una precisa sintonía entre el modo de ver únicamente al individuo y los demás miembros del núcleo familiar o bien surgir una más o menos fuerte resistencia de parte de los familiares a aceptar la decisión de sus parientes.

Es evidente que los problemas surgen exactamente en este segundo caso. Si la persona quiere que se respeten sus ideas, y que se supere el obstáculo que representan sus familiares, no le resta más que dejar una declaración explícita de voluntad o encargar a alguien externo a la familia para que haga respetar su propia voluntad no obstante la oposición de los parientes. Nótese que tal declaración de voluntad o la intervención de un tercero (un mandatario) externo a la familia se convierte en necesarios solamente en el caso en el cual el sujeto interesado se dé cuenta de que sus familiares están completamente en contra de su voluntad, a falta de declaración expresa es posible que éstos busquen hacer prevalecer la suya. Tal declaración sería superflua en el caso en el que discutiendo con la familia el individuo se percate que hay una total disponibilidad (por respeto o por convicción que aquí poco importa) de aceptar su punto de vista.

En este último caso, si se mira bien, no hay necesidad de declaración alguna. De hecho, aquella persona puede morir en paz sabiendo que en el momento oportuno serán sus seres queridos, la esposa o el esposo, el hijo o los hijos, las nietos, el amigo más querido en el caso en que no tenga familiares, los que llevarán a cabo la voluntad por él expresada informalmente en vida. Su silencio significa solamente que él está en sustancia de acuerdo con lo que sus familiares decidirán hacer con su cadáver. Si él - por un motivo o por otro - no se fiaba de ellos podía haberlo pensado antes de morir y hacer sin dificultad una declaración expresa. 
En relación con la disposición del propio cuerpo por el tiempo sucesivo a la muerte debería ser similar al testamento. Cuando las relaciones al interior de la familia son claras y ya en vida, de común acuerdo, se decidió todo aquello que se tenía que decidir, esto es superfluo. Tanto es verdad que en este caso el de cuius no ejercita su poder de testar, porque está seguro que su herencia será atribuida, como él lo desea a sus parientes más cercanos. El honor de testar corresponde en cambio a quien pretende dar disposiciones precisas sobre sus bienes porque tal vez desea algo diferente respecto de sus familiares, dejar una parte también a personas extrañas.

Un mecanismo análogo podría valer también para las disposiciones sobre el propio cuerpo post mortem y su ausencia podría ser interpretada como acuerdo implícito respecto de lo que decidieran hacer sus familiares. Si él no ha dejado disposiciones al respecto podemos razonablemente presumir que confía en lo que sus parientes decidirán para él. En este caso compete a los familiares ocuparse de los restos, de proveer un funeral y sepultura, así también les corresponderá decidir si consienten o no la extracción de órganos. Nadie mejor que ellos para conocer la voluntad de su familiar pues aunque si el ahora difunto no ha dejado testamento, no ha manifestado públicamente su deseo es simplemente porque está tranquilo respecto de los sujetos que disfrutarán de sus bienes y sobre el hecho de éstos respetarán su voluntad también en lo relacionado con el destino de sus restos.

Existe por tanto una semejanza entre la disposición de los bienes y aquella del cuerpo cuando hay un acuerdo razonable entre la voluntad del difunto y la de sus familiares. La analogía en cambio puede resultar a primera vista menos evidente cuando estamos en presencia de un conflicto de voluntad. Para aquél que atañe la disposición de los bienes es del todo oportuno, como el resto de la ley prevé, que una cuota de sus restos permanezca indisponible, reservada a sus parientes más cercanos desde el momento que se 
considerara profundamente injusto que todos los bienes del de cuius se le dejen a un extraño y que no reciban nada la consorte y los hijos.

Esto testifica la importancia que el ordenamiento jurídico le atribuye a la familia en la sucesión por causa de muerte, que en nuestro ordenamiento, al punto de incluirla en la carta constitucional, en donde el artículo 42 establece que al legislador sólo le compete la determinación de los límites "de la sucesión legítima y testamentaria”, cubriendo así con una garantía constitucional los intereses de la familia. Hay que admitirlo, es sorprendente que mientras la sucesión de los bienes de un difunto se inspira en la tutela de los vínculos familiares más estrechos se quiera excluir radicalmente estos mismos vínculos cuando en la discusión se menciona el cuerpo del difunto y todos sus órganos.

Dichos vínculos, sin embargo - como ya habíamos visto-, no pueden hacerse valer al grado de que prevalezcan sobre la decisión individual del de cuius, cuando ésta tiene relación con lo más íntimo a uno mismo, es decir, al propio cuerpo. En este caso la facultad de disponer del testador no es limitada en algún modo por la tutela de los más estrechos vínculos familiares. Precisamente porque no tendría ningún sentido hablar de "legitimidad" de los familiares sobre los órganos del difunto; pero esto no desvanece la analogía con el testamento. En realidad es como si se dijera que el cuerpo del difunto (aunque no se pueda configurar como un bien) entrara nuevamente en la parte disponible de los bienes del de cuius y no en la indisponible. De cualquier modo cuando existe un testamento es necesario escuchar la voluntad del difunto y si la facultad de testar permanece en parte sujeta al vínculo familiar de éste no se deberá tomar en cuenta respecto de las disposiciones que dejó el de cuius respecto de su cuerpo.

Cuando en cambio no existe un testamento podemos sostener razonablemente que el de cuius, como era del todo conocido, sus bienes serian para quienes el deseaba que fueran (es decir, a sus familiares), así también era conocido 
que el hecho de ocuparse de sus restos mortales serian sus familiares y que éstos lo harán de acuerdo con sus ideas y sus valores. Si no estaba convencido de esto - repetimoshabria tenido que manifestar su voluntad, si no lo hizo es porque no tenía motivos para dudar que sus familiares lo respetarían.

Llegamos así a una segunda conclusión muy importante: los familiares no pueden oponerse a una declaración de voluntad de uno de sus familiares, cuando ésta se refiera al destino de su cuerpo, y en ausencia de una declaración son ellos a quienes se les interpela y se les pide decidir por él, también sobre su cuerpo, respetando sus ideas y sus convicciones.

Las cosas, sin embargo, en la práctica son más complicadas de cuanto pareciera desde un punto de vista exquisitamente teórico. Una vez admitido que al faltar una declaración de voluntad expresa del difunto sean sus familiares los que tengan el poder de decidir por él, sobre la suerte de su cuerpo lo deberán hacer teniendo en cuenta la convicción del difunto y no la de ellos. Pero precisamente esta tarea - la de decidir por él, como si lo hubiera hecho- puede poner a los familiares, que sinceramente intentan respetar la convicción de su difunto, en una situación más o menos difícil. Veámoslo con un ejemplo.

Un individuo habría podido tener una aversión por un funeral religioso sin haber tocado nunca el tema con la familia. Aquella aversión podía simplemente derivar de su coherente comportamiento ateo que tuvo durante su vida. Entonces si aquel individuo no habló nunca y tampoco dejó escrito algo al respecto es porque considera del todo obvio que su coherencia en vida será respetada por sus familiares también cuando esté muerto. Pero ¿qué pueden decidir estos últimos en relación con la alternativa de la sepultura o cremación, o, en modo más lacerante, respecto de la donación o no donación de órganos?

Concentrémonos sobre todo en la primera alternativa. Si el individuo no se ha manifestado al respecto, sus familia- 
res pueden presumir razonablemente que el problema de la cremación, en realidad, ni siquiera lo haya considerado. Esto porque en el ámbito de nuestra cultura (por lo menos hasta ahora) se considera normal que los cadáveres sean sepultados pero no que sean incinerados. Si el difunto hubiera querido optar por una elección en el momento actual, entonces poco difusa, el seguramente lo habría dicho. ${ }^{28}$ Por esta razón un silencio al respecto puede sin dificultad ser interpretado como un presumible consenso por la sepultura. A lo más todos los familiares podrán preguntarse sobre el tipo de sepultura. Pero si él no afrontó el argumento quiere decir en resumidas cuentas que le era indiferente terminar bajo tierra o en un nicho de cemento.

Mucho más complicada es para los familiares la segunda alternativa. Cuando el individuo antes de morir nunca manifestó su parecer respecto a la donación de sus órganos es para ellos aún más difícil decidir, rápidamente después de la muerte, si dan o no su consentimiento para que sean extraídos los órganos. Sobre todo en este caso resulta más problemático deducir de las convicciones y del comportamiento que tenía en vida el difunto su propensión a la donación de los órganos o una postura contraria.

Todo indica que un ateo coherente, si no dejó disposiciones respecto de su funeral, no quería un rito religioso. Y de cualquier modo un funeral, al máximo, ofendería su memoria. Con la extracción, sin embargo, sucede algo que perturba más. Es el hecho de que su cuerpo sea desmembrado. Sus familiares ¿deberian, por ejemplo, deducir que al tratarse de una persona que cuando vivía siempre estaba disponible a ayudar a los demás también estaría dispuesta, al

28 De cualquier modo, bajo un perfil jurídico, debía expresarse. La ley italiana hasta hace poco tiempo exigia para la cremación la forma testamentaria. Una nueva Ley en la materia (núm. 130 de 2001) está inspirada en una mayor libertad consintiendo la cremación aunque faltara la disposición testamentaria del difunto. Esta Ley, sin embargo, pasa por alto, desde mi punto de vista, las perplejidades que tienen que ver con la autorización de la cremación de los restos inhumados desde al menos diez años y enterrados desde al menos veinte años. $C f r$. infra, pp. 167-189. 
estar muerta, a ceder sus órganos?, ¿pueden estar seguros que su solidaridad llegaría a tanto?

Sólo en un caso puede estarlo verdaderamente, es decir, en la hipótesis en la cual aquella persona al menos una vez haya puesto en peligro su vida para salvar la vida de un extraño. Si él, cuando estaba vivo, en dicha situación estaba listo para sacrificar su vida es razonable presumir que, de muerto, estaría dispuesto a sacrificar sus órganos. Sin querer excluir este caso, se deberá entonces conceder que ésta es más bien excepcional. Generalmente los seres humanos no renuncian a su vida por los demás y no existe ninguna regla moral o jurídica que lo pueda obligar a hacerlo.

Por otro lado, generalmente, cuando un individuo en vida nunca se expreso sobre el uso post mortem de sus órganos nos orillaría a pensar que él no tenía una opinión favorable respecto de la extracción. Si él, cuando vivía, no renunció a su vida ¿por qué, de muerto, debería estar dispuesto a renunciar a sus órganos?

Se podría fácilmente replicar que la vida es vida y la muerte es muerte, que una persona que apreciaba tanto la vida podría ser completamente indiferente a lo que le sucedería después de su muerte. Cierto, esto es posible. Pero permanece el hecho de que su forma de pensar respecto de la vida y la muerte nunca fue comunicado a sus familiares, éstos se encontrarán atormentados ante la duda ¿habría o no habría consentido la extracción de sus órganos?

En este caso los familiares ni siquiera pueden presumir razonablemente que era lícito para él si hubiera tenido que elegir entre inhumación y cremación. Esto por la simple razón que los cadáveres en nuestra cultura son sepultados siempre, sus órganos son utilizados solamente a partir de las últimas décadas. Los familiares entonces no pueden presumir si su familiar se manifestó al respecto ya que sostenía que la donación de órganos, como la sepultura, era del todo obvia y natural. Al contrario, en todo caso, éstos deberían sostener que la donación de los órganos (como la cremación) permanezca como una decisión que se dé por 
descontada cada día. Es verdad que el caso de la cremación es un poco diverso al de los trasplantes, desde el momento que en los últimos años la opinión pública ha solicitado discutir sobre este tema. Pero ¿podemos actualmente sostener que la cultura de la donación sea a tal punto difundida entre la gente como para ser considerada como algo del todo normal, como la sepultura del cadáver? Si así fuera los familiares podrian tranquilamente interpretar el silencio de su familiar como un consentimiento a la donación; pero debemos honestamente admitir que hoy en nuestro país no es así. No se podría decir que con el tiempo esto cambie, pero no podemos considerarlo hasta ahora como un dato adquirido. He aquí, porque el punto crucial a destacar en el caso de los trasplantes es el comunicativo.

Si queremos afrontar en modo éticamente sostenible el problema no queda otro camino que el de hablar y sobre todo con la familia, porque en el caso del silencio son nuestros familiares los únicos moralmente legitimados para decidir por nosotros. Cancelar por ley el papel de los familiares y equiparar el silencio de un individuo con su consentimiento ${ }^{29}$ son caminos intransitables. Por una parte porque el cadáver está ligado antes que nada al afecto de una familia y por otra porque aquel silencio actualmente podría ser interpretado como un desacuerdo más que como un consentimiento a la donación.

El único camino por seguir — no hay otro- es el de estimular, a través de una adecuada campaña informativa, en cada persona, la necesidad de expresarse en la familia, con las personas más queridas, respecto a la disponibilidad o no de donar sus órganos. En el momento oportuno, si el sujeto no declaró públicamente su voluntad, serán sus familiares los que responderán a esta delicadísima cuestión, pero lo harán con el corazón tranquilo porque estarán cons-

29 Para una reciente crítica filosófica al criterio del silencio-consentimiento véase Parisoli Marzano, M. M., "La volpe e il corvo, ovvero la favola del silenzio-assenso", Materiali per una storia della cultura giuridica, XXXI, 1, 2001, pp. 165-188. Cfr. también Parisoli Marzano, M. M., Norma e natura: una genealogia del corpo umano, Nápoles, Vivarium, 2001. 
cientes de que respetan la voluntad privadamente expresada por su familiar.

Todo esto no se realiza de un día para otro, pero para recoger buenos frutos se requiere sembrar buenas semillas. Hoy es el tiempo de sembrar, pero si - como sucede en Italia- sembramos en tierra poco fértil no recogeremos nada de bueno. En lugar de una auténtica cultura de la donación tendremos - lo estamos viendo- un consenso manipulado con información poco clara. El camino que hemos propuesto seguir - se nos objetará- es largo y la necesidad de órganos siempre mayor. ${ }^{30}$ ¿Qué hacer entonces hoy?

En el momento inmediato no debemos abandonar algunos principios éticos fundamentales. El primero es el vínculo familiar que es moralmente ineludible, cuando el difunto no haya dejado una declaración de voluntad. Los familiares podrán actualmente encontrarse ante una duda atroz, sin embargo, hoy solamente ellos podrán asumir el peso de tal decisión. Con el tiempo probablemente se desatará el nudo, pero si actualmente se trata de cortarlo es justo que sean ellos en hacerlo. Por la estrecha relación de afecto que subsiste entre la persona que ahora ya no existe más y ellos que permanecen aquí, corresponde exclusivamente a ellos una decisión tan comprometedora. Un poco como la de los padres en relación con los hijos, cuando se encuentran frente a la duda si consienten o no la intervención una ope- ración riesgosa.

Este ejemplo nos permite hacer evidente una diferencia significativa entre las dos situaciones y una posible vía de salida en el caso de los trasplantes. Los padres de un modo $\mathrm{u}$ otro deben decidir entre consentir o no una operación riesgosa; sin embargo, lo que no podrán hacer es callar. Pero ¿por qué los familiares de un difunto interpelados sobre la donación de sus órganos deberían responder?, ¿por qué el silencio del muerto no podría continuar con el silen-

30 Cfr. Sirchia, G., "Il trapianto d'organi in Italia: organizzazione, attività, prospettive”, Aggiornamenti sociali, 1996, pp. 201-210. Los datos más recientes se pueden encontrar en el Centro Nazionale Trapianti: www.ministerosalute.it/trapianti. 
cio de los vivos? Si es, como creemos, lícito, el silencio del difunto podría continuar simplemente con el silencio de los familiares, ante la duda ¿cómo debería ser interpretado este segundo silencio? $\mathrm{Si}$, como se ha visto, un único silencio actualmente no se puede interpretar como consentimiento de donación, no podrán ser con mayor razón dos silencios. Los dos silencios, por el contrario, se suman recíprocamente y no pueden más que excluir la extracción de los órganos. Esto puede suceder - he aquí el segundo principio-sólo a condición de que el silencio del difunto sea equilibrado por un explícito consenso de sus familiares. Hay que desear que las palabras puedan vencer el silencio, pero dos silencios no podrán nunca valer como consentimiento.

\section{UN CORAZÓN QUE LATE}

Lo que hemos dicho presupone, obviamente, que se trata de cadáveres y sobre este presupuesto se ha fundado nuestra legislación, como la de muchos otros países; pero la hipótesis más inquietante es que los sujetos a los que se extraen los órganos aún no son cadáveres. ${ }^{31}$

Para aclarar este aspecto es necesario antes que nada considerar como se define la muerte de una persona. Hasta finales de las últimas décadas se sostenía que la muerte era el término total e irreversible de cada función vital del organismo y ésta se verificaba al detenerse el sistema cardiocirculatorio y al no existir respiración. Es esta la definición tradicional de muerte como muerte cardiorrespiratoria o cardiopulmonar. Con el desarrollo de las técnicas de reanimación nos encontramos, en la década de los setenta, de frente a la posibilidad de mantener con vida a personas en condiciones desesperantes garantizando artificialmente la respiración y la continuación de los latidos cardiacos. Si

31 Sobre este punto tengo un proyecto para publicar, en colaboración con la doctora Rasangela Barcaro, una colección (antología) de las voces críticas más recientes y aún desconocidas en nuestro país. 
por un lado los procedimientos de reanimación permitían en cierto modo salvar la vida de los pacientes, gracias a la ayuda de un respirador que suplía momentáneamente algunas funciones vitales del organismo; por otro, implicó para otros pacientes que nunca salieran del estado de coma, el corazón continuaba latiendo, pero su cerebro estaba irremediablemente dañado, muerto. El coma era entonces irreversible y, vistas las condiciones clínicas generales, el sujeto parecía destinado a ir en contra de detener el sistema cardiocirculatorio en breve tiempo.

Fue así que se encargo a una Comisión de médicos de Harvard estudiar la cuestión y en el año de 1968 publicó un informe final en el que se afirmaba que los pacientes que se encontraban en condición de coma irreversible en realidad no eran ya pacientes sino cadáveres. ${ }^{32}$ Nace así la nueva definición de muerte como el cese irreversible de todas las funciones cerebrales, en muchas legislaciones sobre trasplantes constituye la condición necesaria para efectuar la extracción de órganos. Aquella que hasta ahora ha sido una "prognosis" infausta, se convierte en un diagnóstico de muerte.

La nueva definición obtiene el aplauso casi general. Ésta, de hecho, consentía desconectar el respirador sin que esto implicara algún problema ético y de ética profesional, desde el momento que el sujeto sometido a las medidas de reanimación era preventivamente declarado muerto. También

32 Cfr. Ad Hoc Committee of the Harvard Medical School, "A definition of Irreversible Coma", Journal of American Medical Association, 205, 6, 1968, pp. 337-340. La necesidad de una nueva definición de muerte era así anunciada "Hay dos razones por las cuales existe necesidad de una definición: 1) los progresos de las técnicas de reanimación y de soporte que han llevado a aumentar los esfuerzos por salvar a aquellos que se encuentran efectados por traumas graves. Algunas veces estos esfuerzos implican acontecimientos parciales, así que el resultado es un individuo al cual aún le late el corazón, pero su cerebro está irremediablemente dañado. El daño es grave para los pacientes que sufren la pérdida permanente del intelecto, para su familia, y para aquellos que necesitan una cama de hospital que éste ocupa; 2) los criterios obsoletos de la definición de muerte pueden conducir a controversias al obtener órganos para los trasplantes" (p. 337). Mientras el primer motivo lleva a sostener lícito la interrupción del tratamiento, el segundo revela el objetivo práctico relacionado a los trasplantes. 
consentía que se mantuviera el respirador después de haber declarado la muerte del paciente, con el objetivo de tener un banco de órganos frescos - predominantemente con el corazón latente - para que pudieran ser utilizados en trasplantes, mismos que podían llevarse a cabo en las mejores condiciones.

Si bien se podía estar de acuerdo sobre desconectar el respirador, el mantenerlo conectado en tales condiciones no representaba un acuerdo fácil. Se trataba de tener un tipo de vida simulada en un organismo humano, pero con un objetivo totalmente ajeno a él. Quisiéramos subrayar que esta nueva posibilidad ofrecida por la técnica desde el inicio pudo producir efectos destructivos para la ética de la profesión médica. El riesgo para el médico era el de comenzar a considerar a los pacientes no como humanos que sufrían una enfermedad o muertos a causa de ésta, sino como máquinas a las que sus partes podian ser a placer sustituidas o al límite (en el caso de muerte cerebral) retomadas.

No obstante, la definición de Harvard - sobre todo por las ventajas que ofrecían los trasplantes - no encontró resistencia. Se quitó simplemente el obstáculo definiendo como muerto al paciente sujeto a la extracción y considerando decisivo el hecho de que utilizando sus órganos se podía salvar otras vidas humanas. El efecto benéfico inmediato terminó por ocultar los riesgos a largo plazo. Una de las pocas voces fuera del coro fue la de Hans Jonas que rápidamente puso el dedo en la yaga, con un artículo que se convirtió en un clásico de la literatura. ${ }^{33}$ Sin embargo, su

33 Cfr. Jonas, H., "Morte cerebrale e banca di organi umani: sulla ridefinizione pragmatica della morte", en Jonas, H., Tecnica, medicina ed etica. Prassi del principio responsabilità, cit., nota 8, pp. 167-184. En estas páginas brevemente se recoge un breve comentario escrito en 1968, el verdadero artículo es el titulado Against the Stream, escrito en 1970, pero publicado en 1974 y dos escritos posteriores de 1976 y 1985, señal de la constante atención que Jonas tenía sobre este tema. Entre los tres primeros críticos de la definición de muerte cerebral encontramos al filosofo Josef Seifert que, como católico, representó la única voz de desacuerdo en la Pontificia Academia de la Ciencia, la que en diciembre de 1989 convocó a un grupo de trabajo para examinar la nueva definición de muerte, que al final llegaría a aceptar. Los resultados del encuentro se encuentran en el volumen White, R. J. et 
crítica resultó entonces una oscura especulación filosófica, carente de un real fundamento científico, desde el momento en que la muerte cerebral era interpretada como la disolución del centro integral del organismo entero y como muerte de aquella individualidad corpórea en su totalidad. Si esta premisa, en el fondo, sostenía el carácter científico de la definición de la muerte cerebral soportada por la convicción de que las funciones vitales del cuerpo de un individuo cerebralmente muerto podría mantenerse por breve tiempo.

Jonas ya desde entonces contestó todo esto y lo hizo con base en las investigaciones, desarrolladas por él, más destacadas de su tiempo que se fundamentan en contra de las tendencias reduccionistas entonces predominantes de la ciencia: una "nueva biología" centrada en la función del metabolismo y sobre la idea de la unidad psico-física del ser humano. Es cierto, este no es el lugar para profundizar este aspecto. El hecho interesante es que las más recientes pruebas de la ciencia neurológica confirman en gran parte lo establecido de Jonas. ${ }^{34} \mathrm{Al}$ menos dos argumentos son aquí atentamente evaluados.

El primero es que la muerte cerebral como cesación irreversible de todas las funciones del encéfalo no resulta efectivamente diagnosticable sobre la base de los criterios operacionales y tests standars actualmente previstos. Esto surge de un estudio de Troug y Fackler, de los primeros años de la década de los noventa, que nos parece enseguida fue desmentido. ${ }^{35}$ De este trabajo resulta que los pacientes que actualmente disfrutan los criterios de la definición de la muerte cerebral no presentan necesariamente la perdida irreversible de todas las funciones del cerebro. Un aspecto

al. (eds.), The Determination of Brain Death and Its Relationship to Human Death, Ciudad del Vaticano, Pontificia Academia de la Ciencia, 1992.

34 An der Heiden, U.; Roth, G. y Schwegler, H., "Die Organisation der Organismen: Selbsterhaltung”, Funktionelle Biologie und Medizin, 5, 1985, pp. 330-346; cfr. también Roth, G. y Dicke, "Das Hirntodproblem aus der Sicht der Hirnforschung", en Hoff, J. y der Schmitten (eds.), Wann ist der Mensch tod? Organverpflanzung und Hirntodkriterium, Reinbeck bei Hamburg, Rowohlt, 1994, pp. 51-57.

35 Cfr. Troug, J. C. y Fackler, "Rethinking Brain Death", Critical Care Medicine, 20, 12, 1992, pp. 1705-1713. 
interesante, aunque hay otros también significativos, ${ }^{36}$ es que alguna parte del encéfalo (hipófisis por ejemplo) pueden continuar induciendo la secreción de algunas hormonas también en condiciones de muerte cerebral y los test previstos no verifican si el cerebro de aquel paciente declarado muerto secreta o no tales hormonas. Esto no deriva una consecuencia de notable relevancia desde la perspectiva jurídica. En legislaciones como la nuestra que solicitan un cese "irreversible" de "todas" las funciones cerebrales para declarar muerto a un paciente, en ocasiones se procede a la extracción cuando el donador, según la ley, está aún vivo.

$\mathrm{El}$ segundo argumento sobre el que nos gustaría llamar la atención es cómo los organismos clínicamente definidos en estado de muerte cerebral sobreviven, conectados a las máquinas, más tiempo de cuanto se podría imaginar y esto hace pensar que el cerebro no sea esencial para el funcionamiento del cuerpo entero. En fin, la constatación de que (la presunta) muerte del cerebro sea un indicador de la muerte que se efectuará de manera próxima a todo el organismo se revelada como falsa. Alan Shewmon es el neurólogo que en una investigación de la década de los noventa llegó a esta conclusión, ${ }^{37}$ en ésta ha tratado las consecuencias haciendo una explícita autocrítica: el, católico, que había defendido el criterio de la muerte cerebral es llevado explícitamente a refutar cualquier definición de la muerte sobre la base de criterios exclusivamente neurológicos. La muerte de todo el cerebro (admitiendo que pueda ser verifi-

36 Vale la pena recordar que algunos pacientes declarados muertos y donadores, una vez sujetos a la extracción del corazón han declarado que al momento de la incisión quirúrgica con el aumento de la presión máxima y de la frecuencia cardiaca el corazón aún latía; tanto que algunos años atrás en Inglaterra algunos médicos declararon que llevaron a cabo una intervención quirúrgica de extracción bajo anestesia. A este punto se podría además señalar que los donadores, una vez declarados muertos, eran sujetos a toda una serie de tratamientos médicos para evitar que, como decirlo, que se "enfermaran". Cfr. Morrissey, P. E. y Monaco, A. P., "Un approccio globale al problema della donazione di organi", Minuti, enero de 1998, pp. 27-37.

37 Cfr. Shewmon, D. A., "«Brain-Stem Death", "Brain Death" and Death: A Critical Revelation of the Purported Equivalence”, Issues in Law and Medicine, 14, 2, 1998, pp. 125-145. 
cada) no equivale entonces a la muerte del ser humano. Con la muerte cerebral tenemos la pérdida irreversible de las funciones cerebrales; pero no la muerte del organismo humano y ya que el organismo que es parte integrante de su ser pero no sólo de este ser. El ser humano entonces no está todavía completamente muerto cuando está muerto su cerebro.

En estas condiciones no tiene más sentido mantenerlo con vida, desde el momento que es imposible cualquier recuperación. Pero una cosa es suspender en estos casos el tratamiento, y otra intervenir en él para extraerle los órganos cuando se encuentra aún en aquella condición de ambigüedad de una vida biológica que continúa no obstante el cerebro este encendido (admitiendo, que después esté completamente muerto).

En 1968 contra la definición de la muerte cerebral en línea defensiva expuesta por Jonas proponía en primer lugar suspender la respiración, y después dejar pasar un periodo de tiempo breve, pero suficiente para verificar la ausencia de toda señal de vida, y sólo sucesivamente proceder a la extracción de los órganos. No muy diferente, respecto del éxito práctico, me parece que las más recientes conclusiones de Shewmon, que al rechazar la definición de muerte cerebral no ha negado la laicidad de los trasplantes sosteniendo, sin embargo, que éstos deberían suceder después de la cesación definitiva del latir cardiaco y de la circulación.

La gran interrogativa que se abre es si respetando tales criterios resultarían también fructífero realizar los trasplantes. Las condiciones no serán más optimas y las ventajas más limitadas. Esto es un hecho indiscutible, pero aquí el problema que debemos plantearnos es si las extracciones -como los estudios más recientes que he mencionado certifican- provienen de donadores que están aún vivos o si es exactamente la extracción de órganos es la que provoca su muerte. Las legislaciones que han aceptado la muerte cerebral se fundan sobre el presupuesto de que la muerte del pa- 
ciente se presenta cuando sucede la extracción, pero este presupuesto es una ficción, empíricamente falsa. Si las cosas están en estos términos, podemos preguntarnos si las extracciones, en las condiciones en las que actualmente se practican, son lícitas.

Distinguiré dos perspectivas: una jurídica, respecto del cual solamente haré una breve mención, y una ética, respecto del cual intentaré un primer acercamiento. Sobre la perspectiva jurídica, limitándome a nuestro ordenamiento, el discurso podría fácilmente hacerse extensivo, porque creo se puede concluir que éstos sean completamente ilícitos. Si el presupuesto de la actual legislación es que la extracción provenga de cadáveres, entonces es del todo evidente que si no se verifica una determinada condición no se puede en configurar la legalidad de tal operación.

También en la hipótesis, es decir, en el caso de un explícito consenso de la donación, nos encontraremos, incluso en nuestro ordenamiento, de frente a la imposibilidad de aplicar el artículo 579 del Código Penal, que por otro lado condena severamente el homicidio consentido, porque el consentimiento debería perdurar hasta el momento en el cual de hecho se lleva a cabo la extracción, lo que es objetivamente imposible dado que el sujeto no tiene conciencia.

Bajo la perspectiva ética la extracción podría configurarse como un caso particular de eutanasia. Si el sujeto interesado, que precedentemente había consentido donar los órganos, en el momento en el se realiza la extracción se encuentra de algún modo vivo, esto quiere decir que tenemos que hacer algo con esta especie de eutanasia. No únicamente por piedad de quien se va sino también por solidaridad respecto de los que se quedan. Es diferente respecto del caso paradigmático de la eutanasia arriba considerado (aquel del enfermo terminal que aún consciente pide morir) aquí tenemos un paciente que ha perdido en modo irreversible la capacidad de estar conciente y que, sin embargo, antes de perderla ha decidido donar sus órganos. Ahora bien, si él, estando correctamente informado del hecho que la extrac- 
ción se efectúa cuando su organismo está aún vivo, de igual forma había dado su consentimiento explícito ¿cómo deberíamos evaluar éticamente su decisión?

No se puede pretender que él done sus órganos; aún más si la extracción se lleva a cabo cuando el sujeto se encuentra aún en una condición ambigua entre la vida y la muerte. Pero si decide igualmente hacerlo, deberemos respetar su decisión. Él no tiene algún deber de donar sus órganos, sin embargo, necesita reconocer el derecho de hacerlo también en esa condición extrema. Si, como hemos visto, un enfermo terminal consciente, tiene el derecho de morir para no hacer sufrir a los demás (además de así mismo), un paciente al que el cerebro dejo de funcionar irreversiblemente debería tener el derecho de decidir, cuando esté en las condiciones de poder hacerlo, de sacrificar el poco de vida que le resta por la vida de los otros.

Esta decisión sería de un alto valor moral y requeriría algo más que un mero consenso informado. Sería necesario verificar que la información proporcionada la haya recibido concientemente el destinatario. Sólo una decisión plenamente motivada y consciente podrá justificar éticamente que la extracción de órganos se realice con el respirador encendido y contra-equilibrar el papel concreto en el que se encuentra el sujeto cuando en aquella condición se convierte en objeto de la operación.

Se podría replicar que así el número de los donadores se restringirá notablemente. Cierto, si ya es difícil obtener el consenso de la donación de órganos de cadáveres, será todavía más difícil obtenerlo en el caso en el cual se debiera admitir que la extracción ocurre cuando en realidad no se es aún cadáver. Sin embargo, no existen alternativas éticamente sostenibles: o se desconecta el respirador y después de un tiempo razonable se procede a la extracción, respetando las condiciones ya discutidas, o bien si lo deja encendido, pero entonces no podemos atrincherarnos más detrás de las ficciones de la muerte cerebral y se necesita tener la honestidad de admitir que el paciente no está aún muerto 
cuando se realiza la extracción. El sujeto debe saber exactamente en este caso cuales son los inconvenientes y su decisión debe ser absolutamente consciente.

Falta, sin embargo, preguntarse, como ya en el caso del enfermo terminal que pide morir, si el médico puede proceder a la extracción del corazón mientras el corazón aún late, sin disminuir su ética profesional (y aquí, entre otros, el dilema permanecería irresuelto: de hecho, sólo un cirujano puede realizar esta delicadísima intervención). Si el paciente aún está vivo en el momento de la intervención entonces parecería que es justamente la incisión quirúrgica la que le ocasiona la muerte. Deberíamos por tanto concluir que aunque se admita el valor moral de donar los órganos en aquélla conclusión, ¿el médico debería abstenerse de realizar la intervención para no cumplir un acto de eutanasia?

No creo que se deba llegar a esta conclusión, sin que se ponga en discusión la tesis que precedentemente hemos sostenido. El médico no debe matar a un enfermo terminal que en pleno uso de sus facultades mentales se lo pide, pero el caso que estamos ahora discutiendo es muy diferente. También si el paciente al que el cerebro a dejado de funcionar pero que no está muerto, que le queda un residuo de vida biológica conservada artificialmente no está aún muerto, pero tampoco está vivo. Se encuentra en una zona gris del confín, de la cual lo único que sabemos es que ya está comenzando el proceso de muerte. Además la simple interrupción de aquel tratamiento, el desconectar el respirador artificial, podría ser considerado como un acto de eutanasia. Esto, de hecho, pone fin a aquel proceso. Sostenemos que en aquella situación pueda suspender el tratamiento sin que disminuya su ética profesional. Y esto porque presuponemos que cuando el cerebro de un ser humano se apaga irremediablemente la continuación biológica no tiene sentido y sería solamente una forma de obstinación terapéutica la que se empeñaría en mantenerla que aquella condición. Pero si aceptamos esto, deberemos también admitir que la acción del médico cuando procede a la extrac- 
ción de los órganos no es comparable con matar a un paciente que se lo pide explícitamente. ${ }^{38}$

Él no está matando a alguien que si no fuera por tantos dolores físicos continuaría viviendo, solamente pone fin a un proceso que de cualquier modo sería lícito interrumpir, suspendiendo la terapia intensiva, en el caso que el paciente no hubiese consentido la extracción de sus órganos.

La única diferencia respecto a la suspensión del tratamiento consiste en el hecho de que se mantiene un poco más de tiempo al enfermo con el objeto de proceder a la intervención. En el caso de la eutanasia activa se acorta la vida del paciente evitándole un cúmulo de sufrimientos; en el caso del trasplante, en cambio, se prolonga un poco en el tiempo un residuo de vida con el objetivo de restituirle a otros una más plena y vital. Además en este caso el médico opera por la vida y no por la muerte.

Si tuviéramos la necesidad de un trasplante deseariamos que el donador hubiera dejado las disposiciones que nos garanticen un órgano en las mejores condiciones y asegurarnos así la posibilidad de continuar viviendo. No podemos pretenderlo de él, como no se puede pretender que al estar ahogándonos alguien pusiera en peligro su vida para salvar la nuestra, pero si alguien decidiera hacerlo nos alegraría y su acción sería de gran valor, como lo es el donar los propios órganos sabiendo que en realidad la extracción se realiza cuando aún no se está muerto. No se ve por qué razón el médico de frente a la concreta posibilidad de salvar otras vidas, no pueda aceptar este último y extremo sacrificio.

38 Cfr. en la misma dirección Höfling, W. y Rixen, S., Verfassungsfragen der Transplantationsmedizin. Hirntodkriterium und Transplantationsgesetz in der Diskussion, Tübingen, J. C. B. Mohr (Paul Siebeck), 1996, pp. 97 y ss. En la misma línea Hoff, J., “J. In der Schmitten, Tod?", Die Seit, núm. 47, 13 de noviembre de 1992, p. 56. Quisiera recordar aquí que la hipótesis avanzada de admitir el trasplante de órganos aún no compartiendo el criterio de la muerte cerebral, no encontró en Jonas apoyo, que para el resto, sin embargo, veía en las críticas que entonces en Alemania se estaban difundiendo contra la nación de muerte cerebral, una sorprendente imprevista confirmación de su tesis. Cfr. Jonas, H., "Brief an HansBernhard Wuermeling", Wann ist der Mensch tot?, cit., nota 34, pp. 21-25. 